\title{
DEVELOPMENT OF AN ELISA FOR THE DIRECT MEASUREMENT OF FREE 25OH VITAMIN D
}

N. Heureux*, M. Anciaux, M. Poncelet, F. Mathieu DIAsource Immunoassays, Louvain-la-Neuve, Belgium

L.M. Swinkels, T. Huijs, S. Boerrigter, E. Lindhout, G. Mayer, M. Martens Future Diagnostics B.V., Wijchen, The Netherlands

\section{Introduction}

Almost all circulating $250 \mathrm{OH}$ Vitamin D in serum is bound to Vitamin D Binding Protein DBP (88\%) and Albumin (12\%). A very small fraction, approximately $0.04 \%$ of the $25 \mathrm{OH}$ Vitamin D, circulates in the free, non-protein bound form. ${ }^{1}$

The concentration of DBP is not constant and can be influenced by a number of factors including obesity, ${ }^{2}$ pregnancy, ${ }^{3}$ the use of oral contraceptives, ${ }^{4}$ hormone replacement therapy, ${ }^{5}$ liver disease, ${ }^{6}$ renal disease, ${ }^{7}$ proteinuria ${ }^{8}$ and intensive care. ${ }^{9}$

Furthermore, common genetic polymorphisms in the DBP gene produce variant proteins that differ in their affinity for $250 \mathrm{OH}$ Vitamin D. ${ }^{10,11}$

For thyroid and steroid hormones it has been shown that their in vivo physiological activity correlates better with the free, non-protein bound fraction, than with the total concentration of the hormone in plasma. In such conditions the measurement of the concentration of the free circulating hormone provides more physiologically relevant information. This notion is known as the "free hormone hypothesis". ${ }^{12,13}$ Particularly in situations in which the level of binding proteins is elevated or decreased, the measurement of total circulating hormone may lead to a wrong diagnosis.

The bioavailability of $250 \mathrm{H}$ Vitamin $\mathrm{D}$ may be more complex, since it is a precursor that is metabolized in the kidney to the active $1,25(\mathrm{OH})_{2}$ Vitamin D. However, literature data suggest a role for the measurement of free $25 \mathrm{OH}$ Vitamin D. ${ }^{14-17}$

Here we describe an ELISA that offers the possibility to measure the concentration of free $250 \mathrm{OH}$ Vitamin D in serum

\section{Principle of the Assay}

The Free $250 \mathrm{H}$ Vitamin D ELISA is based on a two-step immunoassay procedure. During the first incubation step free $250 \mathrm{OH}$ Vitamin $\mathrm{D}$ binds to the monoclonal antiVitamin $D$ in the microtiter plate. The in vivo equilibrium between free and bound $250 H$ Vitamin $D$ is minimally disturbed by the use of a specific displacement reagent. After washing, a fixed amount of biotinylated $25 \mathrm{OH}$ Vitamin $\mathrm{D}$ is added to each well. The non-bound biotinylated $250 \mathrm{H}$ Vitamin D is removed by washing and a streptavidin peroxidase conjugate

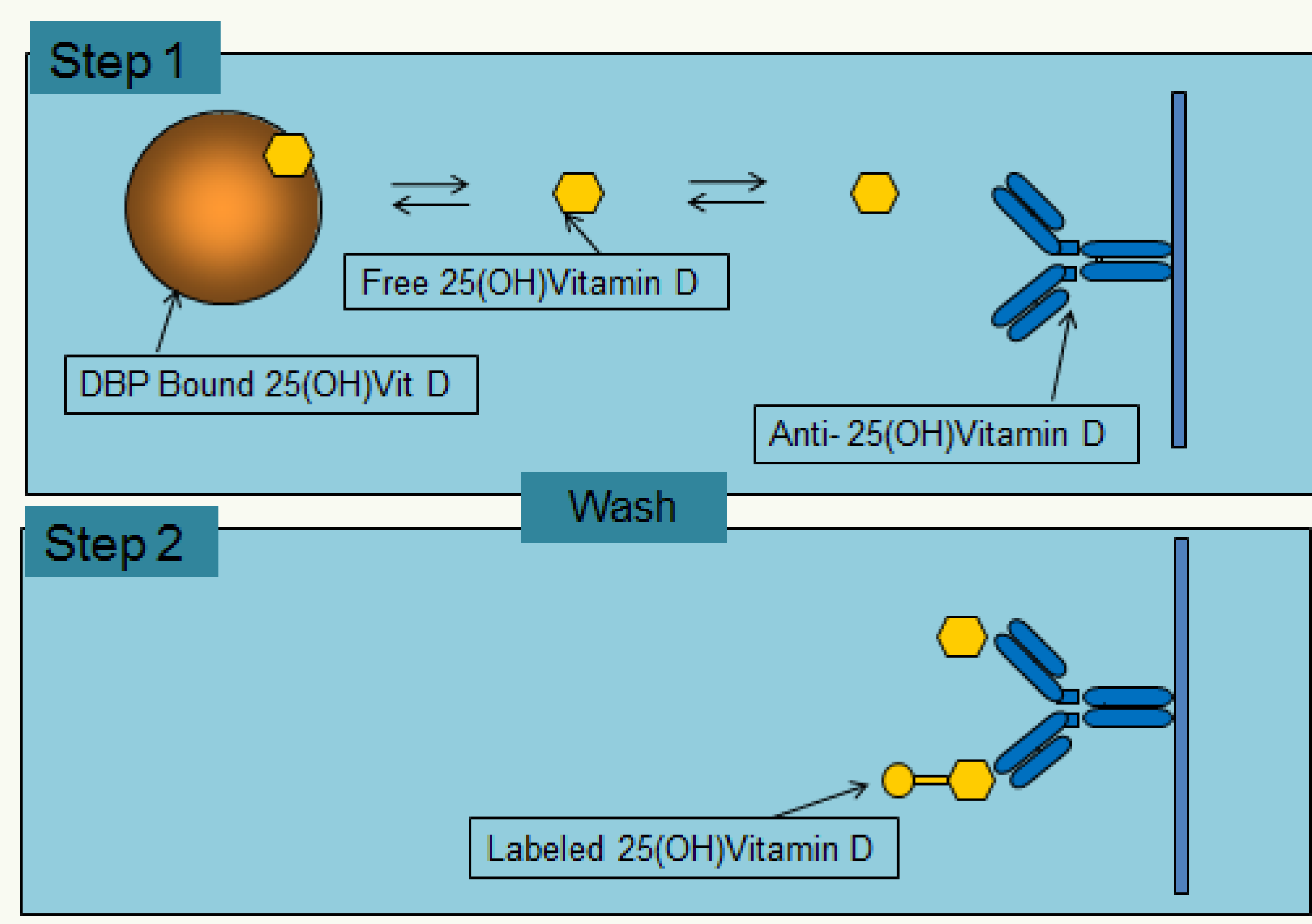

is added. In a next step TMB chromogenic substrate is added. The reaction is then stopped by addition of Stop solution and the absorbance is measured using a plate reader.

The concentration of free $250 \mathrm{OH}$ Vitamin $\mathrm{D}$ in the calibrators was determined using a rate dialysis technique.

\section{Assay Protocol}

\begin{tabular}{|c|}
\hline $90 \mu \mathrm{L}$ Sample Diluent $+10 \mu \mathrm{L}$ Calibrator, Control or Sample \\
\hline \\
\hline Wash $3 \times$ then $100 \mu \mathrm{L}$ Biotin-25OH Vitamin D Reagent \\
\hline $30^{\prime}$ at $37^{\circ} \mathrm{C}$ with shaking \\
\hline \\
\hline Wash $3 \times$ then $100 \mu \mathrm{L}$ Streptavidin-HRP Reagent \\
\hline $20^{\prime}$ at $37^{\circ} \mathrm{C}$ with shaking \\
\hline Wash $3 \times$ then $100 \mu \mathrm{L}$ TMB \\
\hline $15^{\prime}$ at rt, stationary in dark \\
\hline $100 \mu \mathrm{L}$ Stop Reagent \\
\hline$\checkmark$ \\
\hline Read at $450 \mathrm{~nm} \&$ Calculate the results \\
\hline
\end{tabular}

\section{Assay Performance}

\begin{tabular}{|c|c|}
\hline Range & $0-40 \mathrm{pg} / \mathrm{mL}$ \\
\hline Precision & $<10 \%$ \\
\hline LoB & $0.7 \mathrm{pg} / \mathrm{mL}$ \\
\hline LoD & $1.9 \mathrm{pg} / \mathrm{mL}$ \\
\hline
\end{tabular}

Additional experiments have shown that the addition of albumin or Vitamin D Binding Protein to serum leads to a decrease in the observed level of free $250 \mathrm{H}$ Vitamin $\mathrm{D}$.

\begin{tabular}{|c|c|}
\hline Sample & Free 250H Vitamin D (pg/mL) \\
\hline Native sample 1 & 3.25 \\
\hline Native sample $1+60 \mathrm{~g} / \mathrm{L}$ Albumin & 1.95 \\
\hline Native sample 2 & $13.0 \mathrm{pg} / \mathrm{mL}$ \\
\hline Native sample $2+1 \mathrm{~g} / \mathrm{L} \mathrm{DBP}$ & $5.8 \mathrm{pg} / \mathrm{mL}$ \\
\hline
\end{tabular}

\section{Pregnancy and Renal Failure}
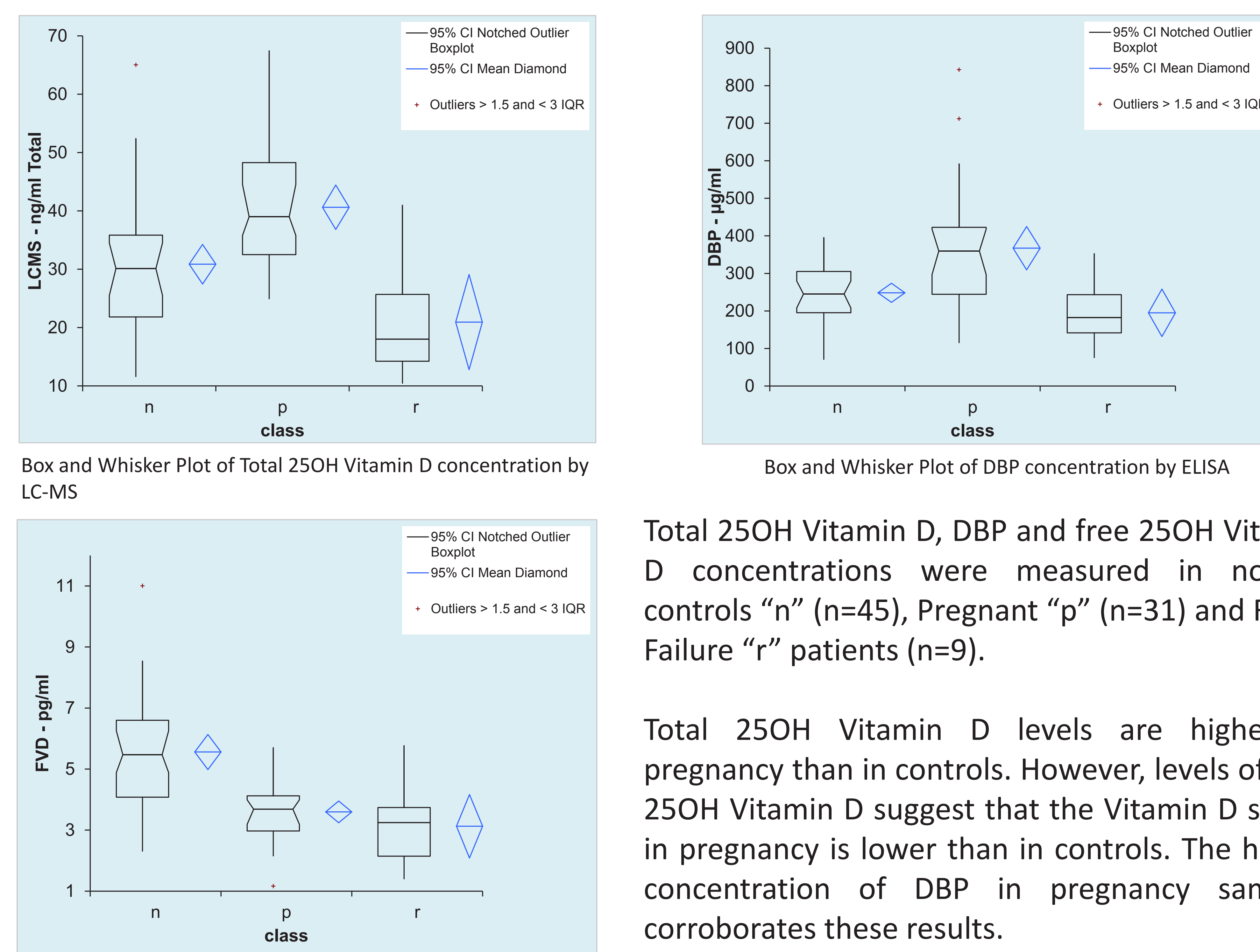

Total $250 \mathrm{H}$ Vitamin D, DBP and free $250 \mathrm{OH}$ Vitamin D concentrations were measured in normal controls " $n$ " (n=45), Pregnant " $p$ " ( $n=31)$ and Renal Failure " $r$ " patients $(n=9)$

Total $250 \mathrm{OH}$ Vitamin $\mathrm{D}$ levels are higher in pregnancy than in controls. However, levels of free $250 \mathrm{H}$ Vitamin D suggest that the Vitamin D status in pregnancy is lower than in controls. The higher concentration of DBP in pregnancy samples corroborates these results.

\section{Discussion}

We present a practical, automatable immunoassay for the measurement of free $250 \mathrm{H}$ Vitamin $\mathrm{D}$ in serum

The addition of albumin and DBP to serum leads to a decrease of the observed level of free $250 \mathrm{OH}$ Vitamin D. This demonstrates that the assay results reflect the level of free $250 \mathrm{H}$ Vitamin D. Measurement of free $250 \mathrm{OH}$ Vitamin D provides a different and possibly more relevant perspective on the Vitamin $D$ status in pregnancy and other conditions of altered Vitamin $D$ binding.

\section{References}

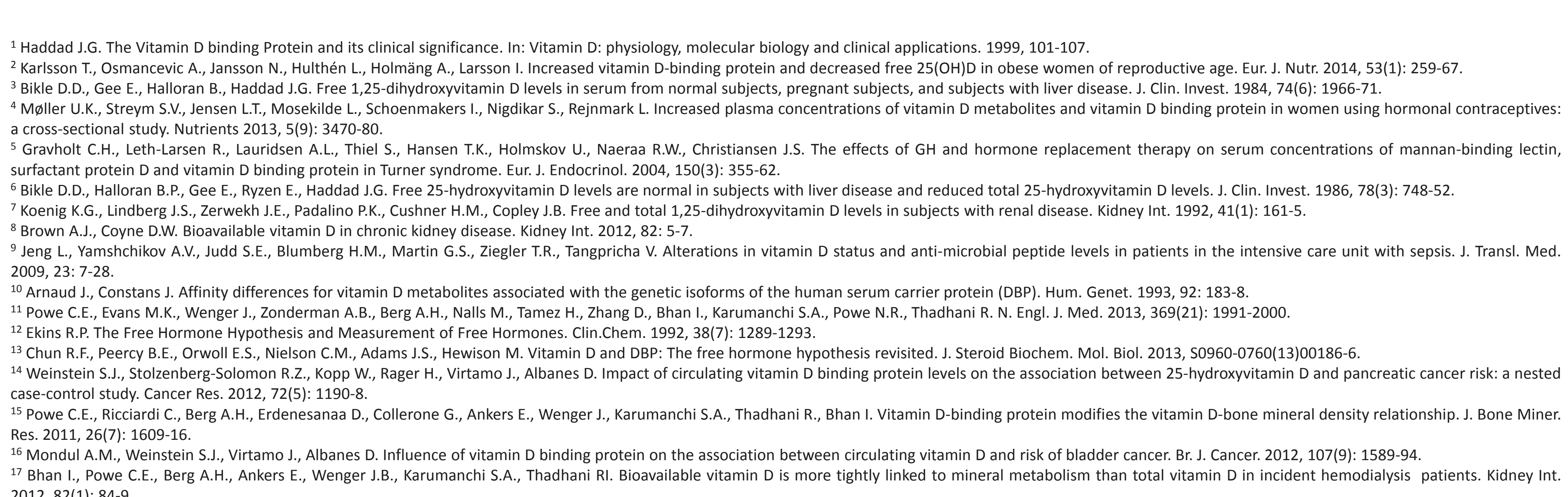

\section{DIA Source}

Join the Scientific Community who talks about free Vitamin D: Linkedln group "Free Vitamin D"

\section{future
diagnostics \\ $4 \begin{aligned} & \text { future } \\ & \text { diagnostics }\end{aligned}$}

